\title{
Designing Application for Performance Assessment to Measure Employee Profesionalism in Goverment Institution
}

\author{
Akbar Iskandar ${ }^{1}$, Rismawati ${ }^{1}$, Robbi Rahim ${ }^{2}$ \\ \{akbar.iskandar06@gmail.com ${ }^{1}$, Rismawati_093@yahoo.co.id ${ }^{2}$,usurobbi85@zoho.com ${ }^{3}$ \} \\ Informatics Engineering, STMIK AKBA, Makassar, Indonesia ${ }^{1}$, School of Computer and \\ Communication Engineering, University Malaysia Perlis, Kubang Gajah, Malaysia ${ }^{2}$
}

\begin{abstract}
In goverment and private institution, there is often a problem in performance assessment system. It is caused by using manual analysis system and excel application that leads to a biased assessment system. The objectives of this research are 1) to develop and implement performance assessment software to measure employee professionalism in government institution based on employee performance targets. 2) to create employee performance assesment software that meets the objective criteria. The method used in this research was waterfall development model. The research was conducted from September 2015 to January 2016 at the education office of South Sulawesi. The research data were obtained through (1) Direct observation to the object of research. (2) Study of literature. The test was done by using black box and data analysis techique using descriptive analysis. The result of the research explains that performance assessment software developed were able to run and function very well without bug, then the descriptive analysis also obtained information that this software fulfill the objective criteria. It is shown that the result of assessment can be displayed according to target and the target which was input into the system. In addition, it can be operated easily and does not a long time in assessing the employee performance.
\end{abstract}

Keywords: assessment, fair, empoyee performance, measurment, evaluation

\section{Introduction}

Performance assessment is defined as a form of performance assessment that has been conducted based on quantitative and qualitative standar predetermined in an istitution or organization[1] [2] [3]. The assessment of work performance in goverment institution is carried out by comparing between the implemented activities and the plan set. [4] [5]. Recently performance assessment is based on aspect of performance planning both at individual level and unit level or organizational unit by focusing on the result, target and benefits achieved even though analysis is done semi computerized. Considering the condition that changes every time in line with technological advances especially on internet in globalization era, [6] the goverment isntitution need to be capable to adjust all the environtment and keep developing goverment institution which must focus to provide the best and fair service to members of society.

Therefore, to know the performance and the service quality given, the assessment must be conducted. The forms of assessment vary and the most popular and does not need more time is 
computer-based assessment application which is commonly called the decision-making system [7] [8]. In addition, it has a patent intelligence to take a fair decision [9]. The forms of measurment and assessment are closely related. When doing assesment, the measurment is also done where the result of measurement is a basis to assess the object assessed[10][11]. Reffering to regulation of Indonesia Government no. 46 of 2011 which discusses the applied rules. In this regulation explains that to realize the coaching of civil servants, especially in education office of South Sulawesi province, the assessment of employee performance which focuses on the applied assessement i.e. performance assessment must be done. The performance assessment system in goverment regulation no. 46 of 2011 is called DP3 and in 2014 the government of Indonesia fixed and implement the system of employee performance assessment although in its implementation, it is still calculated by using application microsoft excel.

Considering the condition that occurs in system of employee performance assessment in Education Office of South Sulawesi Province, they still use semi computerized application i.e microsof excel. Where is known that microsoft ecxel can not fulfill the need of the users because most of assessors are not accustomed to use formulas in microsoft excel, it needs longer time to process the data, it has lower system of data safety and there is no application that combines the database according to the assessment format used. Based on the current condition, the writers conduct the research on Designing application for performance assessment to measure the employee profesianils based on Employee Performance Target (EPT) at Education Offce in South Sulawesi.

\section{Research Methods}

The methods applied in designing this application using waterfall model is Requirement, Design, Implementation, Verification and Maintanance [12]. The location of reaearch activity in South Suawesi Province, in provincial education office. Futhermore, in obtaining preliminary data, the researchers did observation and made documentation as a reference in desingning employee performance software. The testing technique was done by using black box testing method and the technique of data anlysis is descriptive analysis. The phases of designing software by using waterfall model can be seen in figure 1

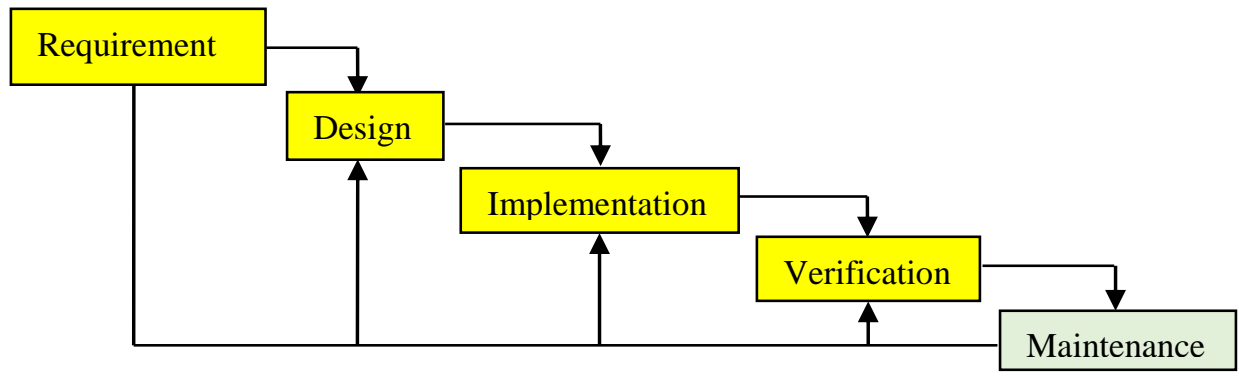

Fig. 1. Model of performance assessment system design. 
Explanations:

$>$ Requirement: a way that can be done to get information abeout the aspects assessed through interview or observation related to system requirements.

$>$ Design: performing a system design both on hardware and software by considering the information obtained in observations and interviews about the assessment system conducted in the field.

$>$ Implementation: In this phase, designing performance assessment software is based on the specifications required. It starts from interface design to coding.

$>$ Verification: in this phase, the system is tested or evaluated based on the purpose of application design.

$>$ Manitanance: this phase will be done after the previous four phases have been completed by modifying and handling problems in its implementation.

\section{Result and Discussion}

\subsection{The results of manual analysis based on the preliminary data findings}

Manual calculations in accordance with the findings of preliminary data are as follows:

1. Formula in calculating Employee Performance Target:

a. Quantity Aspect:

Output Realization (RO)

Output Target (TO) $\times 100$

b. Quality Aspect:

$\frac{\text { Quality Realization (RK) }}{\text { Quality Target (TK) }} \times 100$

c. Time :

1,76 x Time Target (TW) - Time Realization (RW)

d. Cost Aspect:

Time Target (TW)

1,76 x Cost Target (TB) - Cost Realization (RB)

Cost Target (TB)

2. Calculation of EPT Realization on job task

$>$ Carrying out financial administration

1) Coordinate with Financial sub section in terms of financial administration of institution, administration, teachers and principals.

Solution:

a) Quantity Aspect

Dik: $\quad \mathrm{RW}=1$

$\mathrm{TW}=1$

Result : $\frac{1}{1} \times 100=100$

b) Quality Aspect

Dik: $\quad \mathrm{RK}=100$

$\mathrm{TK}=100$

Result : $\frac{100}{100} \times 100=100$

c) Time 
Dik : $\quad$ Wighted score $=1,76$

$$
\begin{array}{ll}
\mathrm{TW} & =12 \\
\mathrm{RW} & =12
\end{array}
$$

Result : $\frac{1,76 \times 12-12}{100} \times 100=76$

d) Calculation $=100+100+76=276$

Score of EPT achievement $=276 / 3=\mathbf{9 2 , 0 0}$

Carrying out office documentation

1) List the school inventory items granted from Education Office of South Sulawesi Province

a) Quantity aspect

Dik: $\quad \mathrm{RO}=1$

$$
\mathrm{TO}=1
$$

Result : $\frac{1}{1} \times 100=100$

b) Quality aspect

Dik: $\quad$ RK $=95$

$$
\text { TK }=100
$$

Result : $\frac{95}{100} \times 100=95$

c) Time

Dik: $\quad$ Weighted score $=1,76$

$$
\begin{aligned}
& \mathrm{TW}=12 \\
& \mathrm{RW}=12
\end{aligned}
$$

Result : $\quad \frac{1,76 \times 12-12}{100} \times 100=76$

d) Calculation $=100+95+76=271$

e) Score of EPT achievement $=271 / 3=90,33$

2) List the entry of the inventory of office supplies

a) Quantity aspect

Dik: $\quad \mathrm{RO}=1$

$$
\mathrm{TO}=1
$$

Result : $\frac{1}{1} \times 100=100$

b) Quality Aspect

Dik: $\quad \mathrm{RK}=95$

$$
\mathrm{TK}=100
$$

Result : $\frac{95}{100} \times 100=95$

c) Time

Dik : $\quad$ Weighted score $=1,76$

$$
\mathrm{TW}=12
$$

$$
\mathrm{RW}=12
$$

Result : $\quad \frac{1,76 \times 12-12}{100} \times 100=76$

d) calculation $=100+95+76=271$

e) score of EPT achievement $=271 / 3=\mathbf{9 0 , 3 3}$

Preparing report on performance development of UPTD (Technical Implementing Service Unit) PK (Special Education) and PLK (Special Service Education)

1) Make financial reports and performance measurement

a) Quantity Aspect

Dik: $\quad \mathrm{RO}=1$ 

$\mathrm{TO}=1$
Result : $\frac{1}{1} \times 100=100$
b) Quality Aspect
Dik: $\quad$ RK $=95$
$\mathrm{TK}=100$
Result : $\frac{99}{100} \times 100=99$
c) Time
Dik : $\quad$ Weighted score $=1,76$
$\mathrm{TW}=12$
$\mathrm{RW}=12$
Results: $\frac{1,76 \times 12-12}{100} \times 100=76$
d) Calculation $=100+99+76=275$
e) $\quad$ Score of EPT achievement $=275 / 3=\mathbf{9 1 , 6 7}$

3. Calculation of EPT realization on Additional tasks and creativity

* Carrying out other official duties ordered by boss in accordance with the field of duty to do the tasks successfully.

Table 1. Additional TAsks

\begin{tabular}{cll}
\hline No. & \multicolumn{1}{c}{ Additional Tasks } & Score \\
\hline 1. & Additional Tasks carried out in a year for 1-3 events & 1 \\
2. & Additional Tasks carried out in a year for 4-6 events & 2 \\
3. & Additional Tasks carried out in a year 7 events or more & 3 \\
\hline
\end{tabular}

Source: PP (Goverment Regulation) No. 46 of 2011 on performance assessment of civil servant

Findings on additional data and creativity

Dik : $\quad$ Target $=7$

Realization $=7$

Therefore the score $=\mathbf{3}$

4. Overall calculation of EPT achievement

$$
\begin{aligned}
& =92,00+90,33+90,33+91,67 \\
& =364,33 / 4 \\
& =91,08+3
\end{aligned}
$$

Therefore score of EPT achievement $=\mathbf{9 4 , 0 8}$

\subsection{Result of Applicaton Design of Employee Performance Assessment}

Measurement, assessment and evaluation are inseparable fom each other and are sequential, since the results of the assesment can not be found if the results of the measurement have not been obtained and the assessment results will become standar in doing evluation to provide instruction in the form of recomendation or decison making on the object that is being assessed.[10][13][4]. Therefore, the login form of employee performance assessment software can be seen in Figure 2. 


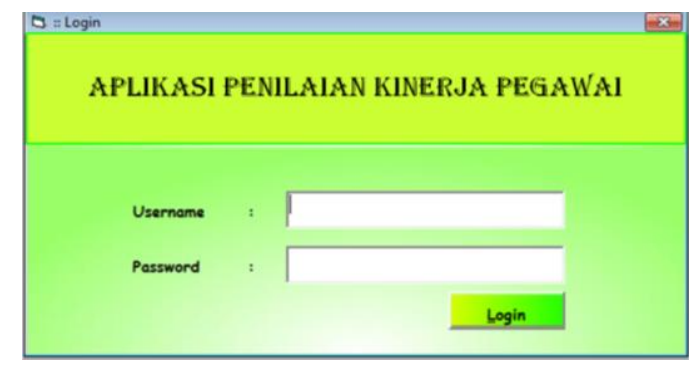

Fig. 2. Login Form of admin and employee assessor

When the performance assessment application icon is activated, it will appear login form and then the user is asked to input the username and password to login into the program. If user and password are input correctly then the system will give the permission. Otherwise, if the user and password are wrong, system will refuse and provide information that the user that is input is wrong. Therefore the existence of login form and other computer security are very important to protect data from irresponsible parties[14].

Then, in this assessment application, there are two access rights i.e. admin level and user level that later will use this system. Assessors who possess access right to do assessment are for those who have been registered by the admin. With the correct user and password, the user will be free to make an assessment of the employees who are mandated to be assessed. In addition, it is also provided a form that can be used to enter the name of the assessor who will be tasked to conduct an assessment of civil servant who are in education department of South Sulawesi Province. This also provides form of data of employees who will be assessed and data needed are employee number, Name, level, position and work unit. More details can be seen in Figure 3:

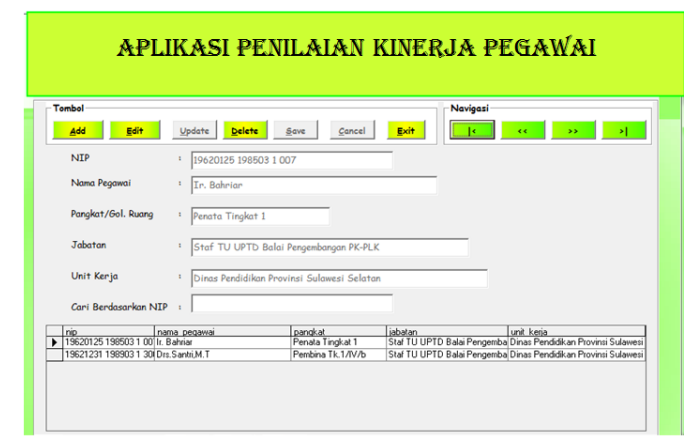

Fig. 3. Form of data of empoyee who will be assessed

Furthermore, it will be explained about realization form which contains the realization of the employee targets achieved during the first period in which the targets contain the data of assessors, employees who are being assessed, job duty, credit score, quantity, quality, time and cost for one period and form of realization based on the target. It can be seen in Figure 4. 


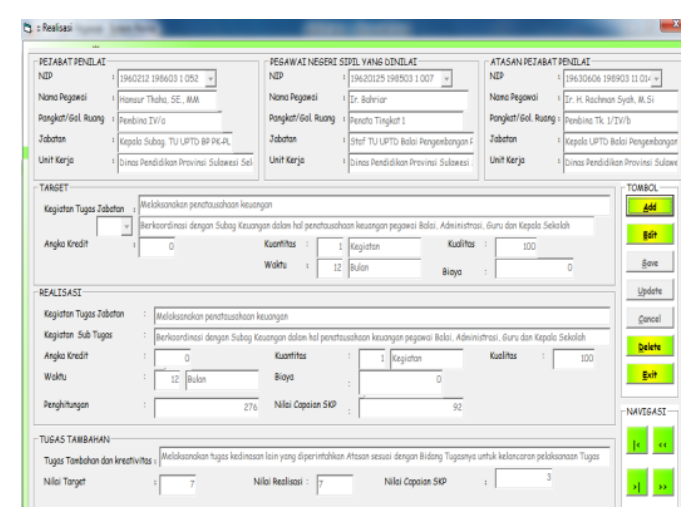

Fig. 4. Form of Realization based on the target

In addition, assessment undertaken to asses achievement targets as described previously also provides a form to conduct an assessment of employee behavior such as service, commitment, cooperation, integrity, discipline, leadership and appearance. The form can be seen in Figure 5.

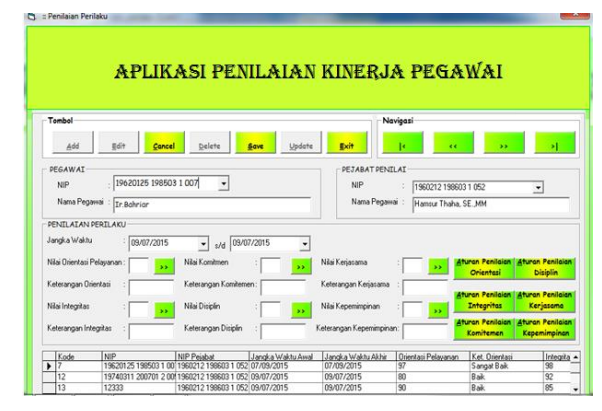

Fig. 5. Assessment form of employee behaviors

\section{Conclusion}

Application of Employee performance assessment is a software that use to measure the preformenace of an employee based on the predetermined aspects. Referring to the results of the previous design and discussion, it can be concluded that using performance assessment software can provide fair treatment for all employees and impartial to anyone because the develeped application will automatically do calculation based on achievement and target provided. In addition, the application is easy to use and does not require more time to get the information assesssment results.

\section{References}

[1] J. Yadav, "A Study of Performance Appraisal System of Employees at Cement Industry," Int. J. Adv. Res. Ideas Innov. Technol., vol. 4, no. 1, pp. 594-598, 2018. 
[2] L. Rajak and D. K. Mishra, "An Analytical Study of Human Resource Management Practices and Its Influence on Employees Satisfaction," Int. J. Adv. Res. Comput. Sci. Manag. Stud., vol. 6, no. 3, pp. 6-11, 2018.

[3] S. T. Ahamed, P. T. M. Niyas, and R. A. L. M, "Identify the Significance of Performance Appraisals on Employee Work Improvement in Software Development Organizations," Int. J. Sci. Res. Publ., vol. 8, no. April, pp. 399-404, 2018.

[4] A. Kharola, R. Mamgain, and A. Jain, "Artificial Neural Network (ANN) based novel Performance evaluation technique," PM World J., vol. VII, no. III, pp. 1-12, 2018.

[5] D. B. Sareen, "Research Article Relationship Between Strategic Human Resource Management and Job Satisfaction," Int. J. Curr. Res. Life Sci., vol. 7, no. 3, pp. 12291233, 2018.

[6] R. Rahim, H. Nurdiyanto, A. S. A., D. Abdullah, D. Hartama, and D. Napitupulu, "Keylogger Application to Monitoring Users Activity with Exact String Matching Algorithm," in Journal of Physics: Conference Series, 2018, pp. 1-4.

[7] Jasri, D. Siregar, and R. Rahim, "Decision Support System Best Employee Assessments with Technique for Order of Preference by Similarity to Ideal Solution," Int. J. Recent Trends Eng. Res., vol. 3, no. 3, pp. 6-17, 2017.

[8] D. Siregar, D. Arisandi, A. Usman, D. Irwan, and R. Rahim, "Research of Simple Multi-Attribute Rating Technique for Decision Support," in Journal of Physics: Conference Series, 2017, pp. 1-6.

[9] M. Mesran, M. Syahrizal, S. Suginam, N. Kurniasih, A. D. Gs, and R. Rahim, "Expert System for Disease Risk Based on Lifestyle with Fuzzy Mamdani," Int. J. Eng. Technol., vol. 7, pp. 88-91, 2018.

[10] A. Iskandar, E. Virma, and A. S. Ahmar, "Implementing DMZ in Improving Network Security of Web Testing in STMIK AKBA,” Int. J. Eng. Technol., vol. 7, pp. 99-104, 2018.

[11] Mansyur, Syahrul, and A. Iskandar, "Assessing the Critical Thinking Ability of Junior High School Students in Makassar and Gowa in South Sulawesi," Int. J. Assess. Eval., vol. 24, no. 3, pp. 25-35, 2018.

[12] Oktafianto et al., "Dismissal Working Relationship using Analytic Hierarchy Process Method," Int. J. Pure Appl. Math., vol. 118, no. 7, pp. 177-184, 2018.

[13] A. Iskandar and M. R. H, "Item Quality Analysis Instrument In The College Entrance Test in The View of The Expert Validator,"International Conference ADRI - 5 "Scientific Publications toward Global Competitive Higher Education," 2018, pp. 364-375.

[14] E. Hariyanto and R. Rahim, "Arnold's Cat Map Algorithm in Digital Image Encryption,” Int. J. Sci. Res., vol. 5, no. October, 2016. 